\title{
Spotting ignition of larch (Larix gmelinii) fuel bed by different firebrands
}

\author{
Guang Yang ${ }^{1} \cdot$ Jibin Ning $^{1} \cdot$ Lifu Shu $^{2} \cdot$ Jili Zhang ${ }^{3}$. \\ Hongzhou Yu ${ }^{1} \cdot$ Xueying Di $^{1}$
}

Received: 20 August 2020 / Accepted: 22 October 2020 / Published online: 24 March 2021

(C) Northeast Forestry University 2021

\begin{abstract}
Spot fire increase the difficulty of fire-fighting and threaten public safety, and therefore it is important to study ignition probabilities of fuel bed by different firebrands, in order to understand ignition mechanisms and analyze the formation of spot fires. This will provide an important basis for further study to improve the fire-fighting efficiency and reduce casualties. In this study, the ignition probabilities of larch (Larix gmelinii) fuel beds with different moisture levels and packing ratios by diffreent firebrands, including cones and twigs of different sizes, was investigated. Ignition experiments were conducted at different wind speeds generated by fans. The results show that, regardless of moisture content and packing ratio, ignition probability is zero when there is no wind. Both moisture content and wind speed significantly influence ignition probability, while packing ratio has almost no effect. The maximum moisture
\end{abstract}

Project funding: This work was funded by the Sub topic of 13th Five-Year-Plan National Key Research and Development Project (2017YFD0600106-2), National Natural Science Foundation Project $(31,400,551,31,870,644)$.

The online version is available at http://www.springerlink.com.

Corresponding editor: Yu Lei

Xueying Di

dixueying@126.com

1 School of Forestry, Northeast Forestry University, Harbin 150040, People's Republic of China

2 Key Laboratory of Forest Protection, Research Institute of Forest Ecology, Environment and Protection, Chinese Academy of Forestry, State Forestry Administration, Beijing 100091, People's Republic of China

3 Research Centre of Cold Temperate Forestry, Chinese Academy of Forestry, Harbin 150086, People's Republic of China content at which firebrand ignition occurred was $50 \%$, and ignition probability increased with wind speed and decreased with moisture content. Cones have the highest ignition probability, followed by large twigs and by small twigs. Ignition probability is also affected by firebrand shapes and sizes that determine their potential heat and contact area to the fuel bed. Two empirical models were established to link ignition probability with fuel properties and wind speed. This study will help clarify the mechanism of spot ignition and reduce corresponding losses.

Keywords Firebrands · Wind speed · Moisture content · Packing ratio $\cdot$ Logistic model $\cdot$ Larix gmelinii

\section{Introduction}

Spot fires are a special type of forest fire with distinct behaviour. When fire intensity is high enough, burning firebrands are carried into the air by fire plumes. Under the action of wind, the firebrands fly to unburned areas and create new burn spots (Bianchi and Defosse 2014). Spot fires exhibit high randomness and are affected by numerous factors such as wind speed, fire intensity and fuel characteristics (Sardoy et al. 2007). The propagation distance can reach dozens of kilometres and firebrands may fly over areas such as rivers and other fire barriers, thus increasing the uncertainty of fire occurrence and the difficulty of firefighting. In 2002, the Heyman fire in Colorado burned nearly 600 buildings (Manzello et al. 2006a). The 2003 southern California fire, which was caused by spot fires, resulted in 20 deaths and destroyed more than 34,000 homes and 300,000 hectares of forest (Manzello et al. 2006b). In 2017, a massive forest fire broke out in Daxing' anling, Inner Mongolia, China; the firebrands flew over a 200-m wide river making it extremely 
difficult to suppress. Thus, understanding the ignition of spot fires is important in forest fire research.

In terms of forest fire propagation, spot fire development consists of three successive stages: firebrand generation, firebrand flight, and the ignition of the fuel bed at the point of landing (Oliveira et al. 2014). These processes are complex and influenced by numerous factors such as firebrand size and state (flaming or smouldering) (Francesco et al. 2011; Pablo et al. 2013; Tao et al. 2020). In addition, the trajectory of firebrands, their size, heat loss, characteristics of the fuel bed and landing point of the firebrand affect the probability of spotting ignition. In addition, environmental factors such as temperature, humidity, wind speed and gravity play an important role in spot fire development. Spot fire occurrence involves physical mechanisms such as fluid dynamics and thermodynamics, chemical mechanisms such as combustion, and although many efforts have been made in this field, much less is known about the mechanism of spotting ignition (Wang 2016).

Previous research on spot fires have been mainly carried out on the three stages of development, among which the generation and propagation of firebrands have been widely studied. Firebrands are burning pieces of material generated from a fire and are mostly cones, twigs, needles, and bark. Since the shape, size and state of a firebrand have a significant impact on the ignition probability (Manzello et al. 2006c), the characteristics of firebrands have been extensively studied. Manzello et al. $(2007,2008)$ found that the firebrand mass for a tree height of $2.4 \mathrm{~m}$ was $2.1-2.3 \mathrm{~g}$, and for $5.2 \mathrm{~m}$ was $3.5-3.7 \mathrm{~g}$. Ganteaume et al. (2011) classified firebrands into three categories based on field and laboratory work: (1) heavy-weight firebrands (cones), which have a certain mass and can sustain their own combustion; (2) lightweight firebrands (needles and thin bark) with large surface areas and short propagation distances; and, (3) light-weight firebrands with low surface areas and volumes. Tarifa et al. (1965) reported that a firebrand will typically be in a smouldering stage after falling onto a fuel-bed. The propagation trajectory of a firebrand depends on the terminal direction velocity and the environmental velocity in the horizontal direction. Based on these considerations, fire scientists have carried out considerable research and established numerous models to predict distance and direction of firebrand propagation (Koo et al. 2010; Morandini et al. 2018). Over a large number of experiments, Albini et al. (2012) found that the maximum rise in height of a firebrand is proportional to the square root of the heat flow intensity of the fire field, and they established a prediction model for the maximum propagation distance. These findings have been widely recognized but research on the ignition probabilities of fuel beds from firebrands has not yet reached a consensus.

The size, shape and state of the firebrand as well as the characteristics of the fuel bed and environmental conditions affect ignition probability. Manzello et al. (2009) used firebrands from Douglas- fir and Korean pine material to analyse ignition capacities of different fuel beds. The results showed that size and mass of the firebrand and wind speed were key factors in determining whether the fuel bed would ignite. Viegas et al. (2012) ignited fuel beds with bark and cones by imitating the spot fire mechanism. They found that when the moisture content of the bed was less than $5 \%$, the ignition probability reached $90 \%$, and the ignition probability with bark was higher than with cones. Ellis (2011) selected pieces of bark of different sizes as firebrands to ignite needle beds and found that a small-sized firebrand could only ignite a fuel bed under windy conditions. Ganteaume et al. (2009) conducted ignition experiments with branches and bark as firebrands from common European tree species. They found that herbage was easier to ignite than deciduous leaves and ignition probability decreased with an increase in moisture content and packing ratio of the fuel bed. Matvienko et al. $(2016,2018)$ established a 3D physical model of the ignition probability for firebrands; the model fully considered both the heat transfer between the firebrand and fuel, and the heat transfer between different pieces of fuel. They verified this model through ignition experiments.

Although there have been studies on ignition probability for firebrands, most of the studies were qualitative and no quantitative probability models have been developed that relate ignition probability to various influencing factors. For a specific fuel, the probability of ignition depends on the firebrand type, the environmental conditions, and the fuel characteristics. Therefore, it is of great significance to quantitatively study the ignition probabilities for firebrands that may cause spot fires. The purpose of this study is to build an ignition probability model that involves firebrands and environmental variables. The model can be used to analyse the influence of predictive factors on ignition probability and to identify their contributions. As one of the major species in the Daxing' an Mountains of China, the Dahurian larch (Larix gmelinii (Rupr.) Rupr.) is prone to producing spot firebrands once a fire occurs, and firebrands falling on unburned fuel will start fires. Developing ignition probability models for spot fires in the Daxing'an Mountains will provide a powerful tool for local fire management agencies.

\section{Materials and methods}

A pure larch stand in Tahe County $\left(124^{\circ} 38^{\prime} 43.35^{\prime \prime} \mathrm{E}\right.$, $52^{\circ} 28^{\prime} 7.98^{\prime \prime} \mathrm{N}$ ) was selected for sample collection (Fig. 1); three $20 \times 20 \mathrm{~m}$ plots ( Table 1) were randomly identified for collecting needles, cones and twigs from the stand floor, with measures taken to maintain the structural integrity of the needles. 


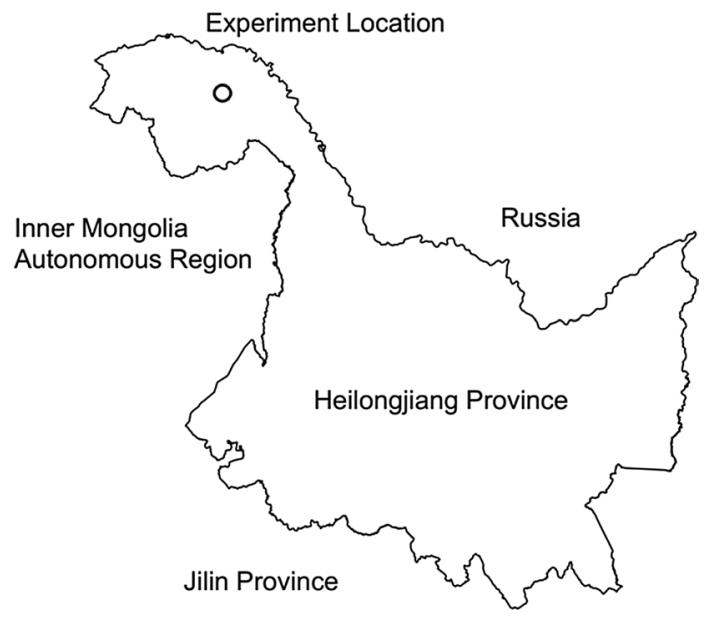

Fig. 1 Location of the experimental stands

Table 1 Preliminary information of larch plots

\begin{tabular}{llllc}
\hline Plot & $\begin{array}{l}\text { Mean DBH } \\
(\mathrm{cm})\end{array}$ & $\begin{array}{l}\text { Mean height } \\
(\mathrm{m})\end{array}$ & Canopy & Fuel load $\left(\mathrm{g} \mathrm{m}^{-3}\right)$ \\
\hline 1 & 25.5 & 15.2 & 0.6 & 693.1 \\
2 & 25.4 & 13.7 & 0.7 & 836.0 \\
3 & 15.3 & 12.1 & 0.8 & 1052.3 \\
\hline
\end{tabular}

\section{Preparation for ignition tests}

The features that characterize a larch needle bed include moisture content and packing ratio. According to a preliminary experiment, when the moisture content of a fuel bed exceeds 55\%, it is difficult to ignite regardless of packing ratio and wind speed. Therefore, five moisture levels (10\%, $20 \%, 30 \%, 40 \%$, and 50\%) were chosen for testing. Eq. 1 calculates moisture content. With the dry weight $\left(W_{D}\right)$ of the fuel bed and the desired fuel bed moisture content (FMC), the wet weight $\left(W_{H}\right)$ of the fuel bed is obtained by adding the weight of water $W_{H}-W_{D}$ to the fuel bed. Needles were quickly and evenly sprayed with the specified amount of water, and sealed in a bag for $24 \mathrm{~h}$ until the water was completely absorbed by the needles. Before each ignition test, the wet weight was re-measured to ensure that the moisture content of the fuel bed was as required for the test.

$\mathrm{FMC}=\frac{W_{H}-W_{D}}{W_{D}} \times 100 \%$

where, FMC is the moisture is content of the fuel bed (\%), $W_{H}$ the wet weight of the fuel bed (g), and $W_{D}$ the dry weight of the fuel bed (g).

The packing ratio of a fuel bed, defined as the ratio between the volume density of the bed and the fuel density, has a significant impact on ignition probability (Bianchi Defosse 2014). To ensure that the packing ratios in the spot fire tests were similar to those in the field, the average height and packing ratio of larch needle beds in the field were determined. The minimum, maximum and average packing ratios of the fuel beds measured in the field were $0.0613,0.0750$, and 0.0898 , respectively, and their average depth was $2 \mathrm{~cm}$. As a result, three drag coefficients chosen for this study were $0.0613,0.0750$ and 0.0898 .

Eq. 2 calculates the packing ratio. Particle density is the ratio of timber weight to volume, fixed for a given fuel bed according to $\mathrm{Li}$ et al. (1986). The particle density of larch needles was $0.702 \mathrm{~g} \mathrm{~cm}^{-3}$. Bulk density is the ratio of fuel bed dry weight to its volume. In this study, $800 \mathrm{~cm}^{3}$ was used the fuel-bed volume and the dry weight for the three chosen packing ratios were $34.4 \mathrm{~g}, 42.4 \mathrm{~g}$ and $50.4 \mathrm{~g}$, according to Eq. 2.

$\beta=\frac{A}{B}$

where $\beta$ is fuel-bed packing ratio, $A$ the bulk density of the fuel bed $\left(\mathrm{g} \mathrm{cm}^{-3}\right)$, and $B$ the particle density of the needles $\left(\mathrm{g} \mathrm{cm}^{-3}\right)$.

\section{Wind speed}

Wind is a major factor affecting the progress of forest fires (Aghajani et al. 2014). Wind speed in forests generally does not exceed $5 \mathrm{~m} \mathrm{~s}^{-1}$ (Sun et al. 2018). Therefore, five wind speeds $\left(0 \mathrm{~m} \mathrm{~s}^{-1}, 1 \mathrm{~m} \mathrm{~s}^{-1}, 2 \mathrm{~m} \mathrm{~s}^{-1}, 3 \mathrm{~m} \mathrm{~s}^{-1}\right.$, and $\left.4 \mathrm{~m} \mathrm{~s}^{-1}\right)$ were selected. An electric ventilation fan was the airflow source to control speed and direction at the surface of the needle bed. The distance between fan and fuel bed was adjusted to get the desired wind speed. A test was started as soon as the wind speed at the surface of the fuel bed reached the desired level.

\section{Firebrand preparation}

Larch needles, cones, small twigs $(<0.64 \mathrm{~cm})$ and large twigs $(>0.64 \mathrm{~cm}<2.54 \mathrm{~cm}$ ) were selected as firebrands. The main firebrand characteristics that affect the ignition probability are size, mass, shape, and moisture content. A firebrand has its strongest ignition capacity when it is completely dry; therefore, dry firebrands were used in this study. In the field survey, calipers were used to measure the collected cones and twigs, such as diameter and lengths, electronic balance were used to measure the weight of cones and twigs (Table 2).

For each combination of bed characteristics and environmental conditions, ignition tests were repeated 30 times on each type of firebrand. To ensure the repeatability of the test, firebrands were prepared so that the diameters, lengths, and 
Table 2 Average firebrand characteristics

\begin{tabular}{llll}
\hline Firebrand & Diameter $(\mathrm{cm})$ & Length $(\mathrm{cm})$ & Weight $(\mathrm{g})$ \\
\hline Cone & 2.0 & 2.0 & 0.6 \\
tw1 (small twig) & 0.4 & 4.0 & 0.4 \\
tw2 (large twig) & 1.0 & 6.0 & 2.3 \\
\hline
\end{tabular}

weights were essentially the same within an error of $1 \%$. For convenience, the two types of twig firebrands were abbreviated as tw1 for small and tw2 for large (Table 2).

\section{Ignition experiment}

Ignition experiments were conducted in an indoor fire laboratory. Uncovered iron boxes $20 \mathrm{~cm}$ long, $20 \mathrm{~cm}$ wide, and $2 \mathrm{~cm}$ high were used for the fuel bed, each placed horizontally at $1 \mathrm{~m}$ above the ground to ensure that the wind simulated at the fuel surface was as natural as possible. An insulation layer was placed under the burning iron box to prevent sparks spreading to other objects.

Each dry firebrand was ignited by placing it in the flame of an alcohol lamp for $30 \mathrm{~s}$; the firebrand was then placed into the center of the fuel-bed by a special test device (Fig. 2). A quartz tube $20 \mathrm{~cm}$ long and $3 \mathrm{~cm}$ in diameter was hung vertically at $5 \mathrm{~cm}$ above the center of the fuel-bed. During the experiment, the firebrand was fed onto the fuel bed through the quartz tube to achieve the same repeated ignition. In the field, a firebrand will be smoldering when it falls on a fuel bed; therefore, in the tests it was necessary to ensure that the firebrands were always smoldering. As soon as the fuel bed ignited (flaming and/or smoldering) and began to spread after a firebrand fell onto it, ignition was considered successful and assigned a value of 1 ; otherwise, the ignition was regarded as a failure and a value of 0 was recorded. In addition, the air temperature and humidity were also recorded.

\section{Data analysis}

\section{Preliminary statistics of test environment}

The ignition probability associated with a firebrand is affected by air temperature and humidity (Bunting and Wright 1974). This study was an indoor ignition experiment with a long test cycle; temperatures and humidities of all ignitions were analyzed to identify environmental variables that might have an impact on ignition probabilities.

\section{Analysis of influencing factors}

ANOVA (analysis of variance) as used to identify the significant environmental factors which impact on the ignition probabilities. For a given type of firebrand, if moisture content, packing ratio and wind speed each have a significant influence on the ignition probability, then two of these factors can be selected as the classification conditions, the remaining factor can be used as the abscissa, and the ignition probability can be used as the ordinate. Histograms formed can be used to analyze the influence of the factor plotted on the abscissa on the ignition probability under the selected classification conditions. Each of the three factors can be analyzed in this way.

However, if only two factors have a significant effect on the ignition probability, then classifying the ignition tests with the no significant factor as a classification condition will be meaningless. In this case, the arithmetic mean of the ignition probability over all values of the no significant factor can be calculated under different combinations of the significant factors to serve as the new ignition probability under different factor combinations. Taking one significant factor as the classification condition, histograms of the variation of this new ignition probability with the other significant factor can then be plotted to analyze the significance of the influence of this latter factor on ignition probability. Both significant factors can be analyzed in this way.
Fig. 2 Schematic diagram of the test device

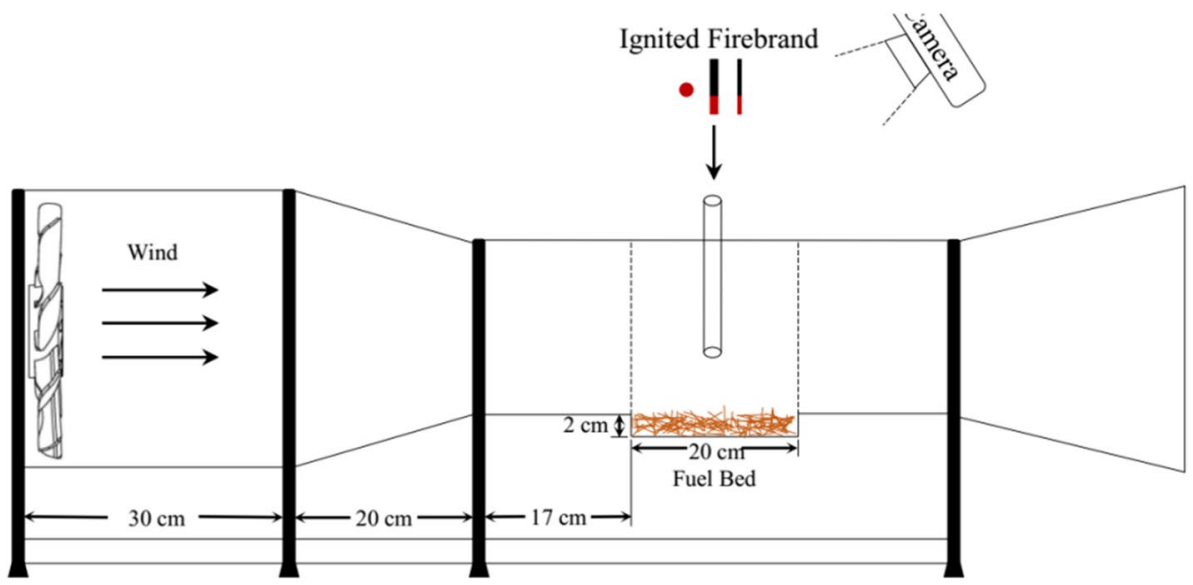


Finally, if only one factor has a significant effect on ignition probability, then the arithmetic mean of the ignition probability should be calculated for each value of this factor. A histogram can be constructed with this factor as the abscissa and the mean ignition probability as the ordinate to analyze its significance on ignition probability.

\section{Ignition probability prediction models}

Two methods were selected for building models for ignition probability prediction, including logistic prediction models and self-built models based on statistics.

A logistic prediction model is a generalized linear regression model (Eq. 3). When the dependent variable has only two outcomes, a prediction model can be built. This method is widely used in forest fire prediction (Garcia et al. 1995; Sun et al. 2018). For each firebrand type, taking the packing ratio, moisture content and wind speed as independent variables and the probability of successful ignition as the dependent variable, the backward regression method can be used to eliminate non-significant factors to establish a prediction model for ignition probability:

$\operatorname{Logit} P=b_{0}+b_{1} X_{1}+b_{2} X_{2} \cdots+b_{m} X_{m}$

For each firebrand type, the form of the logistic model for ignition probability prediction is shown in Eq. 4.

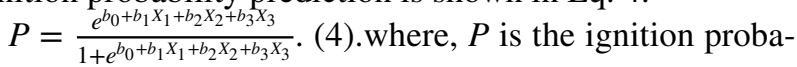
bility (\%), $X_{1}$ the moisture content of the fuel bed (\%, 10-50), $X_{2}$ the packing ratio of the fuel-bed, $X_{3}$ the wind speed $\left(\mathrm{m} \cdot \mathrm{s}^{-1}, 0-4\right)$, and $b_{n}$ the parameters of the model.

Although logistic prediction models are widely used in forest fire occurrence prediction, such a model cannot reveal the detailed mechanism of fuel bed ignition. Therefore, in this study, only the factors that signicantly influence the ignition probability were selected as independent variables, and in accordance with the specific fuel bed conditions and the influence of the factors on the ignition probability for each firebrand type, a prediction model of an appropriate form (on the basis of the minimum average error, (MAE) and simplicity of form) was selected to establish an ignition probability prediction model.

According to the results of an ANOVA, moisture content and wind speed each have a significant effect on ignition probability for each of the three firebrand types. Therefore, the arithmetic mean of the ignition probability over all three packing ratio values under different combinations of moisture content and wind speed is taken as the new ignition probability for the significant factor combinations. By taking the moisture content of the fuel bed as the classification condition, the trend of variation of ignition probability with wind speed can be analyzed to establish an ignition probability prediction model with the wind speed as the independent variable for each of the three types of firebrands with different fuel bed moisture levels. Under different fuel bed moisture conditions, the ignition probabilities associated with the different types of firebrands vary differently with wind speed; therefore, the selected forms of the models are also different. For cones, as the wind speed increases, the ignition probability gradually increases, therefore, models such as $\mathrm{P}=\frac{1}{\alpha+\beta * e^{-w}}, \mathrm{P}=\frac{1}{\alpha+\beta * e^{-\gamma * w}}$, and $\mathrm{P}=\alpha *\left(1-e^{-\beta w}\right)$ are appropriate (where $\mathrm{P}$ is the ignition probability $(\%), w$ the wind speed $\left(\mathrm{m} \cdot \mathrm{s}^{-1}\right)$, and $\alpha$ and $\beta$ denote the parameters of the model. For twigs, the rate of increase in the ignition probability gradually increases as the wind speed increases, so $\mathrm{P}=\alpha * e^{w}, \mathrm{P}=\alpha * e^{\beta * w}, \mathrm{P}=\alpha+\gamma * e^{\beta * w}$ was chosen. On the premise of a low MAE value, the model with the simplest form should be selected as the prediction model. Based on these criteria, the prediction models for cones and twigs take the forms $\mathrm{P}=\frac{1}{\alpha+\beta * e^{-w}}$ and $\mathrm{P}=\alpha * e^{w}$, respectively. The parameters of the prediction models for the three types of firebrands were analyzed with the change in moisture content, and prediction models for the parameters were established with the moisture content as the independent variable. An ignition probability prediction model based on moisture content and wind speed was obtained.

Student's t-test was used to assess whether the minimum average error values of the different ignition prediction models for the three firebrand types were significantly different. The MAE is the sum of the absolute values of the differences between the measured and the predicted values, and can be used to evaluate the prediction effect of a model. The smaller the MAE value, the better the prediction effect. The formula for calculating the MAE is Eq. 5:

$\operatorname{MAE}=\frac{1}{n} \sum_{i=1}^{n}\left|P_{i}-\hat{P}_{i}\right|$

where $P_{i}$ is the actual ignition probability $(\%), \widehat{P}_{i}$ the predicted ignition probability (\%), and $n$ the number of samples.

\section{Results}

\section{Basic statistics of the test environment}

Information on temperature and relative humidity during the ignition experiment are shown in Table 3. Average variations during a single test were $1.17^{\circ} \mathrm{C}$ and $2 \%$, respectively. According to the 75 th percentile values, the number of times that the average was exceeded was small. Therefore, it can be considered that each ignition test was performed in a relatively stable environment. 
Table 3 Information on the experimental environment during a single test

\begin{tabular}{|c|c|c|c|c|c|c|}
\hline \multirow[t]{2}{*}{ Index } & \multicolumn{3}{|c|}{ Temperature $\left({ }^{\circ} \mathrm{C}\right)$} & \multicolumn{3}{|c|}{ Relative humidity (\%) } \\
\hline & variation & Minimum & Maximum & variation & Minimum & Maximum \\
\hline Mean & 1.2 & 22.6 & 25.8 & 2 & 36 & 42 \\
\hline Minimum & 0.4 & 20.5 & 21.5 & 1 & 30 & 33 \\
\hline Maximum & 5.1 & 26.3 & 28.4 & 15 & 49 & 52 \\
\hline 25 th percentile & 1.1 & 22.0 & 23.1 & 1 & 29 & 31 \\
\hline 75th percentile & 1.3 & 23.4 & 24.7 & 2 & 34 & 38 \\
\hline
\end{tabular}

Table 4 ANOVA influencing the ignition probability for each firebrand type

\begin{tabular}{llrlrl}
\hline Firebrand & Index & Estimate & Std. error & t-value & $p$ \\
\hline Cone & Intercept & 0.111 & 0.139 & 0.797 & 0.429 \\
& Wind & 0.147 & 0.017 & 8.545 & 0.000 \\
& Moisture content & -0.004 & 0.001 & -3.153 & 0.003 \\
& Packing ratio & -1.579 & 1.650 & -0.957 & 0.342 \\
tw1 & Intercept & 0.035 & 0.059 & 0.596 & 0.557 \\
& Wind & 0.069 & 0.007 & 9.444 & 0.000 \\
& Moisture content & -0.002 & 0.001 & -3.589 & 0.000 \\
& Packing ratio & -0.761 & 0.706 & -1.078 & 0.284 \\
tw2 & Intercept & -0.183 & 0.104 & -1.759 & 0.084 \\
& Wind & 0.169 & 0.013 & 13.159 & 0.000 \\
& Moisture content & -0.003 & 0.001 & -2.871 & 0.006 \\
& Packing ratio & 0.468 & 1.235 & 0.379 & 0.706 \\
\hline
\end{tabular}

\section{Analysis of influencing factors}

Regardless of the type of firebrand, the ignition probability is dependent on wind speed and fuel bed moisture content, whereas the packing ratio has no significant impact on the ignition probability (Table 4).

\section{Influence of wind speed on ignition probability}

Since the packing ratio had no significant effect on ignition probability, it is not necessary to study ignition probabilities associated with firebrand types based on packing ratio. Therefore, the arithmetic mean of the ignition probability for all three packing ratios under the same fuel-bed moisture content and wind speed was calculated as the ignition probability for the corresponding conditions.

With the moisture content of the fuel bed as the classification condition, the change in ignition probability with wind speed for the three types of firebrands is shown in Fig. 3. The ignition probability increases with increasing wind speed for each firebrand type, and under windless conditions, no firebrand can ignite a fuel bed. For the three types of firebrands, the effect of wind speed on ignition probability is affected by the moisture content of the fuel bed. With increasing moisture content, the difference in ignition probability between adjacent wind speeds gradually decreases. For cones, although the ignition probability continues to increase above a wind speed of $3 \mathrm{~m} \mathrm{~s}^{-1}$, the difference is not significant. For tw1 and tw2, when the wind speed is lower than $4 \mathrm{~m} \mathrm{~s}^{-1}$, ignition probability increases with decreasing moisture content but the rate of increase gradually decreases. When the wind speed reaches $4 \mathrm{~m} \mathrm{~s}^{-1}$, the ignition probability increases significantly.

\section{Influence of moisture content on ignition probability}

With the wind speed as the classification condition, Fig. 4 shows the variation in ignition probability with the fuel-bed moisture content for the three types of firebrands. The ignition probability shows a decreasing trend with increasing moisture content for each firebrand. When the wind speed is low, the ignition probability is significantly decreased for all moisture levels. With increasing wind speed, the influence of moisture content on ignition probability gradually decreases. Although the ignition probability continues to show a downward trend with increasing moisture, the differences are not significant.

\section{Ignition probability prediction models}

\section{Logistic prediction models}

The backward regression method was chosen to eliminate non-significant factors to establish a logistic prediction model for the ignition probability for each type of firebrand. Moisture content and wind speed are both considered in the three prediction models. Table 5 shows the parameters of the logistic prediction models for the different firebrand types.

\section{Self-built prediction models}

When the fuel-bed moisture content is constant, the ignition probability due to a firebrand increases with increasing wind speed (Fig. 3). For cones, the rate of increase in the ignition probability gradually decreases with increasing wind speed, and the models for predicting the ignition probabilities associated with cones as a function of the wind speed at different moisture contents are established accordingly. The MAE 


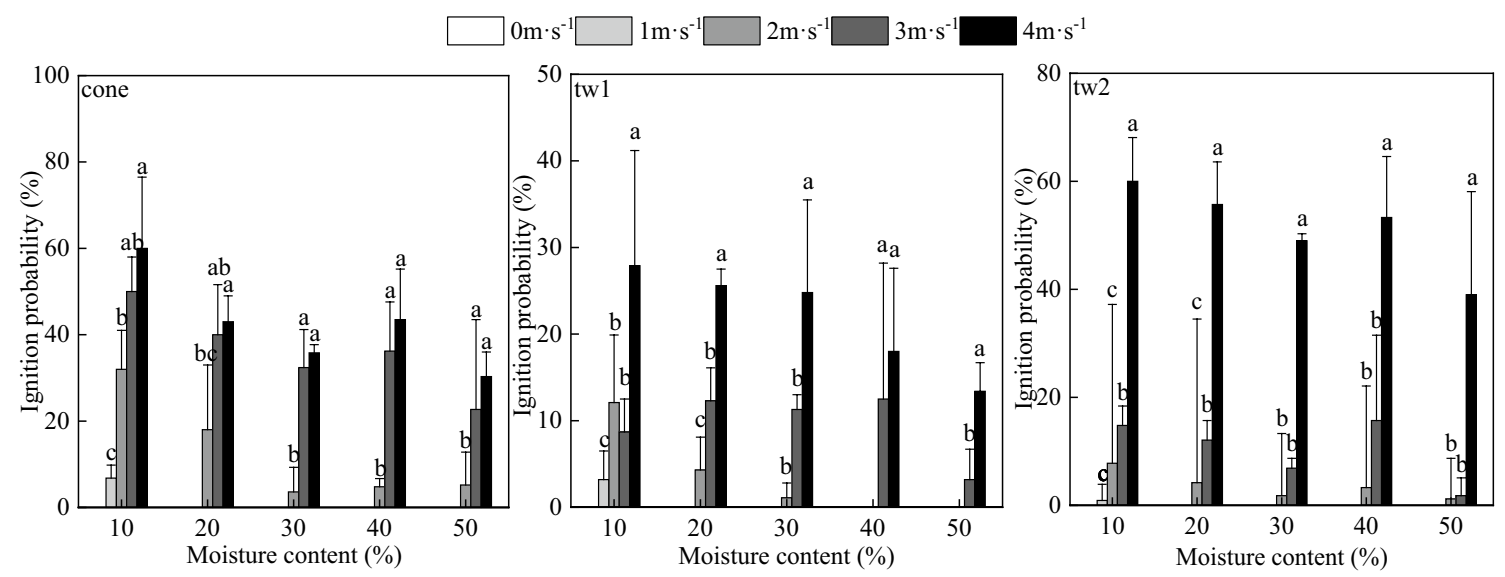

Fig. 3 Variation of ignition probability with wind speed for three types of firebrands under different fuel-bed moisture contents

Table 5 Parameter estimation for the best logistic regression models

\begin{tabular}{llllrl}
\hline Firebrand & Independent variable & $\begin{array}{l}\text { Estimation coef- } \\
\text { ficient }\end{array}$ & SE & Wald chi-square & $p$ \\
\hline Cone & Constant & -3.358 & 0.219 & 236.008 & 0.000 \\
& Wind & 1.104 & 0.062 & 318.289 & 0.000 \\
& Moisture content & -0.035 & 0.005 & 58.902 & 0.000 \\
\multirow{2}{*}{ tw1 } & Constant & -5.136 & 0.393 & 170.798 & 0.000 \\
& Wind & 1.198 & 0.104 & 132.860 & 0.000 \\
\multirow{4}{*}{ tw2 } & Moisture content & -0.030 & 0.006 & 21.642 & 0.000 \\
& Constant & -6.086 & 0.005 & 18.548 & 0.000 \\
& Wind & 1.730 & 0.100 & 302.427 & 0.000 \\
& Moisture content & -0.022 & 0.005 & 18.548 & 0.000 \\
\hline
\end{tabular}

value of a model with the form $\mathrm{P}=\frac{1}{\alpha+\beta * e^{-w}}$ is the lowest. For tw 1 and tw2, the ignition probabilities first increase slowly with increasing wind speed and then increase more sharply. Thus, corresponding models for predicting the ignition probability as a function of the wind speed with different fuelbed moisture contents are established for these two firebrands. A model with the form $\mathrm{P}=\alpha * e^{w}$ has the lowest MAE value. The parameter values and model errors for the prediction models for the different types of firebrands at different fuel-bed moisture levels are shown in Table 6.

For cones, as the moisture content of the fuel-bed increases, the parameters $\alpha$ and $\beta$ of the prediction model show exponentially increasing trends. For parameter models of the form $f_{(\alpha, \beta)}=\gamma * e^{\delta * m c}$, the MAE values are the smallest. In the prediction models for tw 1 and tw $2, \alpha$ decreases approximately linearly with an increase in moisture content, and the parameter model is $f_{(\alpha)}=\gamma+\delta * m c$. The models describing how the prediction model parameters vary with the moisture content are shown in Table 7.

In summary, the ignition probability prediction models and their accuracy for the different types of firebrands with
Table 6 Parameter values and model errors for ignition probability prediction models for different types of firebrands at different fuelbed moisture contents

\begin{tabular}{lllll}
\hline Firebrand & $\begin{array}{l}\text { Moisture } \\
\text { content }(\%)\end{array}$ & $\alpha$ & $\beta$ & MAE (\%) \\
\hline Cone & 10 & 0.0131 & 0.1696 & 4.16 \\
& 20 & 0.0162 & 0.2869 & 4.47 \\
& 30 & 0.0169 & 0.4437 & 5.69 \\
& 40 & 0.0171 & 0.4987 & 6.23 \\
& 50 & 0.0180 & 0.7688 & 2.79 \\
tw1 & 10 & 0.8281 & - & 2.49 \\
& 20 & 0.8117 & - & 0.97 \\
& 30 & 0.7954 & - & 1.52 \\
& 40 & 0.7284 & - & 2.27 \\
& 50 & 0.6120 & - & 2.19 \\
tw2 & 10 & 1.0321 & - & 3.16 \\
& 20 & 1.0141 & - & 3.32 \\
& 30 & 0.9603 & - & 4.03 \\
& 40 & 0.9218 & - & 2.06 \\
& 50 & 0.8979 & - & 5.85
\end{tabular}


Table 7 Models of the parameters

\begin{tabular}{llll}
\hline Firebrand & Parameter & Parameter model & MAE \\
\hline Cone & $\alpha$ & $\alpha=0.0133 * e^{0.0064 * m c}$ & 0.001 \\
& $\beta$ & $\beta=0.1432 * e^{0.0334 * m c}$ & 0.029 \\
tw1 & $\alpha$ & $\alpha=0.9098-0.0052 * m c$ & 0.028 \\
tw2 & $\alpha$ & $\alpha=1.0734-0.0036 * m c$ & 0.007 \\
\hline
\end{tabular}

Table 8 Models of the ignition probabilities associated with different types of firebrands

\begin{tabular}{lll}
\hline Firebrand & Model & MAE (\%) \\
\hline Cone & $\mathrm{P}=\frac{1}{0.0133 * 0.0064 * m c+\left(0.1432 * e^{0.0334 * m c}\right) * e^{-w}}$ & 5.24 \\
tw1 & $\mathrm{P}=(0.9098-0.0052 * m c) * e^{w}$ & 5.37 \\
tw2 & $\mathrm{P}=(1.0734-0.0036 * m c) * e^{w}$ & 3.68 \\
\hline
\end{tabular}

wind speed and fuel-bed moisture content as the independent variables are shown in Table 8 . The MAE values of the cone, tw1 and tw2 models are 5.24\%, 5.37\%, and $3.68 \%$, respectively.

Note: $m c$ denotes the moisture content of the fuel-bed $(\%$, $10-50), w$ the wind speed ( $\left.\mathrm{m} \mathrm{s}^{-1}, 0-4\right)$, and $\mathrm{P}$ the ignition probability (\%).

\section{Model comparison}

Student's t-test was used to compare the MAE values of the two prediction models constructed for each firebrand type. The MAE values of the three self-built models are significantly smaller than those of the logistic prediction models ( $p<0.05$, Table 9) and that the functional forms of the selfbuilt models are more consistent with the actual fuel-bed ignition mechanism.

\section{Discussion}

\section{Moisture content}

For the three types of firebrands, ignition probabilities decreased with an increase in the fuel-bed moisture content; this is consistent with the results of previous ignition probability research ( Plucinski and Anderson 2008; Hadden et al. 2011; Sun et al. 2018; Masinda et al. 2020). The ignition process consists of three stages: (1) the temperature of the fuel-bed increases under the action of the firebrand and water begins to evaporate; (2) the firebrand continues to provide heat and the temperature of the fuel continues to rise until the water is completely evaporated and pyrolysis produces fuel gas; and, (3) the fuel gas mixes with the oxygen in the air and a bright flame appears after a certain concentration is reached. Therefore, as the fuelbed moisture content increases, the heat needed for the ignition of the fuel will increase, and the ignition probability will decrease.

Luke et al. (1978) noted that once the moisture content of the available fuel exceeds $35 \%$, fire ignition becomes extremely difficult. In this study however, it was found that a firebrand is still able to ignite a fuel-bed with a moisture content of $50 \%$, far greater than the value reported by Sun et al. (2018). These results may be mainly attributed to the firebrands selected for testing. Sun et al. (2018) tested the ignition probability associated with cigarette butts which carry less heat than the firebrands considered in this study. Therefore, as fuel-bed moisture content increases, the heat of a cigarette butt becomes insufficient to burn the fuel, whereas the firebrands considered in this study were still capable of causing ignition.

From Fig. 4, it can be seen that for cones, tw 1 and tw2, when wind speed exceeds $4 \mathrm{~m} \mathrm{~s}^{-1}, 3 \mathrm{~m} \mathrm{~s}^{-1}$, and $2 \mathrm{~m} \mathrm{~s}^{-1}$, respectively, the change in ignition probability with increasing moisture is insignificant; however, this does not mean that ignition probability is unrelated to moisture content. It may be that once the wind speed exceeds a certain value, the ignition probability associated with a given type of firebrand is sufficient to cause a fuel-bed with a moisture content no greater than $50 \%$ to produce flames that will spread. Therefore, for a firebrand with sufficient heat, once the wind speed reaches a certain level, the ignition probability depends only on wind speed; under such conditions, the main consideration is the difficulty of causing the firebrand to transition from a smoldering to a flaming state.
Table 9 Results of t-test comparisons

\begin{tabular}{lllllll}
\hline Firebrand & Model & Mean value (\%) & $T$ & $d f$ & $F$ & $p$ \\
\hline Cone & Logistic & 18.09 & 1.8245 & 48 & 139.231 & 0.000 \\
& Self-built & 5.24 & & & & \\
\multirow{2}{*}{ tw1 } & Logistic & 3.46 & 0.9117 & 48 & 6.198 & 0.000 \\
\multirow{2}{*}{ tw2 } & Self-built & 5.37 & & & & \\
& Logistic & 15.52 & 1.7662 & 48 & 104.571 & 0.000 \\
& Self-built & 3.68 & & & & \\
\hline
\end{tabular}



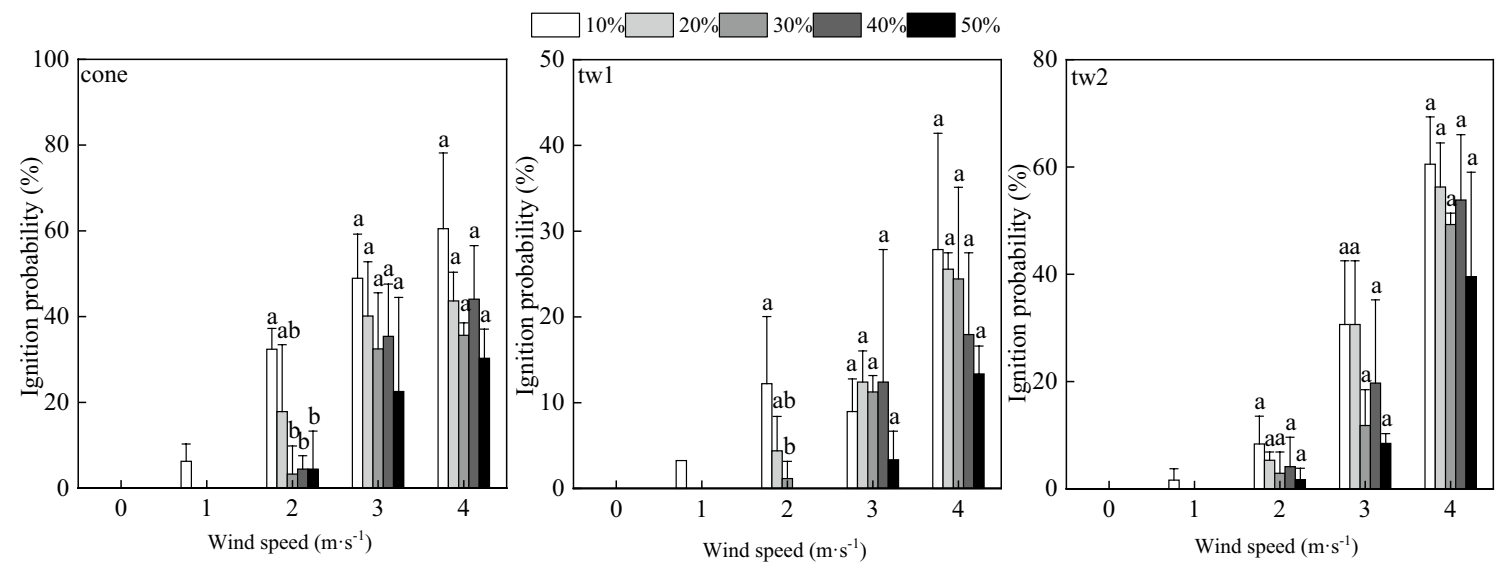

Fig. 4 Variation in ignition probability with moisture content for three types of firebrands under different wind speeds

\section{Wind speed}

In the absence of wind, regardless of fuel-bed characteristics, none of the three firebrands caused fuel-bed ignition. According to the experimental record, each time a firebrand fell onto the surface of a fuel-bed, the firebrand was smoldering. Previous studies have suggested that, for a smoldering firebrand, a certain amount of airflow is necessary to ignite the fuel (Bunting and Wright 1974; Chuvieco et al. 2009; Ganteaume et al. 2009; Sun et al. 2018). At this point, the wind acts on the firebrand and causes it to transition from a smoldering to a flaming state, thereby igniting the fuelbed. Therefore, the ignition probability associated with a firebrand in the absence of wind is 0 .

Under windy conditions, the wind plays dual roles in determining the ignition probability associated with a firebrand. On the one hand, higher airflow can increase the oxygen in the reaction zone and promote combustion; on the other hand, it can also decrease the temperature of the fuel and firebrand, thereby inhibiting combustion. Some previous studies have reported that the ignition probability due to a firebrand initially increases and then decreases with increasing wind speed, reaching a maximum at a certain optimal wind speed (Ellis 2015; Sun et al. 2018). In contrast, Hoffheins (1933) claimed that for a smoldering firebrand, the ignition probability increases continuously with increasing wind speed. It can be seen from Fig. 3 that, according to the results of this study, when the fuel-bed moisture content is constant, the ignition probability increases with increasing wind speed. The differences between the results of previous studies may be attributable to different firebrand characteristics (e.g., size, heat, surface-to-volume ratio).

In this study, although an increasing trend was universally observed, the specific impact of wind speed on ignition probability was different for the different firebrands. For cones, when the fuel-bed moisture content was constant, ignition probability first increased sharply with increasing wind speed and then gradually approached a constant value. For the tw1 and tw 2 firebrands, ignition probability increased slowly at first and then sharply with increasing wind speed. This difference may be due to the different responses of the firebrands to the wind speed during the transition from the smoldering state to the flaming state. Compared with the shapes of tw1 and tw2, the shape of a cone is circular and the surface-area-to-volume ratio is larger. Thus, the surface of contact with the wind is also relatively larger, making the transition more likely to occur at lower wind speeds. However, as the wind speed continues to increase, more of the heat of the cone is taken away until it becomes insufficient to support fuel ignition. Therefore, the ignition probability increases more slowly and it can be predicted that the ignition probability may eventually begin to drop as the wind speed continues to increase (Sun et al. 2018). In contrast, the shapes of the tw1 and tw2 firebrands are cylindrical and their surface-area-to-volume ratios much smaller than that of a cone. Therefore, such a type of firebrand does not show a sensitive response to wind when wind speed is low; thus, it is more difficult to achieve the transition to the flaming state, resulting in a low ignition probability that does not show significant variation. With an increase in wind speed however, the transition is more likely to occur, thus significantly increasing ignition probability.

\section{Packing ratio}

This study indicates that the packing ratio of the fuel-bed had no significant effect on ignition probability. Sun et al. (2018) reached the same conclusion when using cigarette butts to ignite fuel-beds. In contrast, Satho et al. (2003) found that, with an increase in the fuel-bed packing ratio, the ignition probability would increase significantly. These different results can be mainly attributed to two main 
aspects of the influence of the packing ratio on the ignition probability: 1) the heat transfer between individual pieces of fuel; and, 2) the oxygen concentration in the reaction zone. As the packing ratio decreases, there are fewer contact points between individual pieces of fuel in the bed; thus, heat transfer is reduced and the ignition probability is also reduced. However, a decrease in the packing ratio will also increase the oxygen concentration in the reaction zone, thereby increasing the ignition probability. Therefore, the packing ratio plays dual, conflicting roles in influencing the ignition probability, and consequently, different studies may yield different results.

\section{Firebrand types}

Under the conditions of this study, cones had the highest average ignition probability, while the small twig (tw1) firebrand had the lowest. The ignition probability for tw 1 was significantly lower than for the other two types $(p<0.05)$, and there was no significant difference between the ignition probabilities for cones and tw2, the coarse twigs $(P=0.809)$. The ignition probability associated with a firebrand is related to its size and mass, among other characteristics (Manzello et al. 2006a). In this study, the masses of cone and tw2 firebrands are higher than those of the tw1 firebrand, therefore, the ignition probabilities are also significantly higher than that for tw 1 .

\section{Fire management}

In this study, 2250 tests were carried out for each of the three types of firebrands, among which 414, 161 and 337 resulted in successful ignition for cones, tw 1 and tw2 firebrands, respectively. These results are higher ignition probabilities than those reported for cigarette butts and other artificial fire sources (Sale and Hoffheins 1928; Sun et al. 2018). In addition, the firebrands considered in this study are often produced under severe conditions for which the actual ignition probability is higher than that under indoor test conditions. Once a firebrand falls on fuel, it can easily generate a new fire. Therefore, for actual fires in the field, it is necessary to strengthen the monitoring of firebrands and understand their dynamics. The three models developed in this study give ignition probabilities for firebrands falling on larch needles with a prediction accuracy within $6 \%$. Given a known fuel-bed moisture content and wind speed, the ignition probabilities for different types of firebrands can be obtained. This prediction capability is of great significance for allowing measures to be taken in advance to reduce the risk of spot fires and prevent the spread of forest fires.

\section{Conclusion}

This study reveals that the ignition probabilities associated with firebrands of the types investigated are mainly affected by fuel-bed moisture content and wind speed, whereas the packing ratio of the fuel-bed was insignificant. Under windless conditions, a firebrand cannot cause fuel to ignite. The ignition probability decreases with increasing moisture content, but once the wind speed exceeds a certain level, the ignition probability shows no significant variation. The trends in variation of the ignition probability with wind speed differ for cones and twigs. Although the ignition probability increases with increasing wind speed in fuel types, the transition probability of firebrands from smoldering combustion differs at a given wind speed due to the effect of firebrand shapes. Therefore, the ignition probabilities for firebrands of different shapes show different trends with wind speed. In this study, the prediction accuracy of self-built models for the three types of firebrands is significantly higher than that of logistic models, and the self-built models are also more consistent with the mechanisms by which the various factors influence the ignition probability.

This study will be important for guiding future studies of the ignition probabilities associated with firebrands. In future research, it will also be necessary to consider broadleaved or herbaceous fuel-beds with various shapes and sizes of firebrands to improve the prediction of spotting ignition.

\section{Compliance with ethical standards}

Conflicts of interest The authors declare that they have no conflicts of interest.

Open Access This article is distributed under the terms of the Creative Commons Attribution 4.0 International License (http://creativeco mmons.org/licenses/by/4.0/), which permits unrestricted use, distribution, and reproduction in any medium, provided you give appropriate credit to the original author(s) and the source, provide a link to the Creative Commons license, and indicate if changes were made.

\section{References}

Aghajani H, Fallah A, Emadian SF (2014) Modelling and analyzing the surface fire behaviour in Hyrcanian forest of Iran. J For Sci 60(9):353-362

Albini FA, Alexander ME, Cruz MG (2012) A mathematical model for predicting the maximum potential spotting distance from a crown fire. Int J Wildland Fire 21:609-627. https://doi.org/10. 1071/WF11020

Bianchi LO, Defosse GE (2014) Ignition probability of fine dead surface fuels in native Patagonia forests of Argentina. For Syst 23:129-138. https://doi.org/10.5424/fs/2014231-04632 
Bunting SC, Wright HA (1974) Ignition capabilities of non-flaming firebrands. J For 72:646-649

Chuvieco E, González I, Verdú F, Aguado I, Yebra M (2009) Prediction of fire occurrence from live 8 fuel moisture content measurements in a Mediterranean ecosystem. Int J Wildland Fire 18:430-441. https://doi.org/10.1071/WF08020

Ellis PFM (2011) Fuel bed ignition potential and bark morphology explain the notoriety of the eucalypt messmate 'stringbark' for intense spotting. Int J Wildland Fire 20:897-907. https://doi.org/ 10.1071/WF10052

Ellis PEM (2015) The likelihood of ignition of dry-eucalypt forest litter by firebrands. Int J Wildland Fire 24:225-235. https://doi. org/10.1071/wf14048

Francesco C, Guillermo R, Vittorio V, Romano B (2011) Multiscale modeling of transient flows from fire and ventilation in long tunnels. Comput Fluids 51(1):16-29. https://doi.org/10.1016/j.compf luid.2011.06.021

Ganteaume A, Corinne LM, Mercedes G, Carmen H, Marielle J, Teresa F, Pedro PG, José AV (2009) Spot fires: fuel bed flammability and capability of firebrands to ignite fuel beds. Int $\mathbf{J}$ Wildland Fire 18:951-969. https://doi.org/10.1071/WF07111

Ganteaume A, Guijarro M, Jappiot M, Hernando C, Lampin-Maillet C, Pedro Pérez-Gorostiaga José AV (2011) Laboratory characterization of firebrands involved in spot fires. Ann For Sc 68:531-541. https://doi.org/10.1007/s13595-011-0056-4

Garcia CV, Woodard PM, Titus SJ, Adamowicz WL, Lee BS (1995) A logit model for predicting the daily occurrence of human caused forest-fires. Int J Wildland Fire 5:101-111. https://doi.org/10. 1071/wf9950101

Hadden RM, Scott S, Lautenberger C, Fernandez-Pello AC (2011) Ignition of combustible fuel 13 beds by hot particles: an experimental and theoretical study. Fire Technol 47:341-355. https:// doi.org/10.1007/s10694-010-0181-x

Hoffheins FM (1933) Fire hazard tests with cigarettes. J Franklin Inst 216:777-778. https://doi.org/10.1016/S0016-0032(33)90767-X

Koo E, Pagni PJ, Weise DR, Woycheese JP (2010) Firebrands and spotting ignition in large-scale fires. Int J Wildland Fire 19:818-843. https://doi.org/10.1071/WF07119

Li YZ, Zhang SH, Liu H (1986) Variation in density and strength of wood of korean pine and larch from northeast of china and the lumber stress grading. Sci Silvae Sin 22:380-392 ((in Chinese))

Luke RH, Mcarthur AG, Brown AG, Mcarthur AG, Hillis WE (1978) Bushfires in australia. Eur J Surg Oncol 22:354-358

Manzello SL, Cleary TG, Shields JR, Yang JC (2006a) On the ignition of fuel beds by firebrands. Fire Mater 30:77-87. https://doi.org/ 10.1002/fam.901

Manzello SL, Maranghides A, Mell WE, Cleary TG, Yang JC (2006b) Firebrand production from burning vegetation. For Ecol Manage 234:S119. https://doi.org/10.1016/j.foreco.2006.08.160

Manzello SL, Cleary TG, Shields JR, Yang JC (2006c) Ignition of mulch and grasses by firebrands in wildland-urban interface fires. Int J Wildland Fire 15:427-431. https://doi.org/10.1071/WF06031

Manzello SL, Maranghidesa A, Mella WE (2007) Firebrand generation from burning vegetation. Int J Wildland Fire 16:458-462. https:// doi.org/10.1071/WF06079

Manzello SL, Cleary TG, Shields JR, Maranghides A, Mell W, Yang JC (2008) Experimental investigation of firebrands: generation and ignition of fuel beds. Fire Saf J 43:226-233. https://doi.org/ 10.1016/j.firesaf.2006.06.010

Manzello SL, Park SH, Cleary TG (2009) Investigation on the ability of glowing firebrands deposited within crevices to ignite common building materials. Fire Saf J 44:894-900. https://doi.org/10. 1016/j.firesaf.2009.05.001

Masinda MM, Sun L, Wang GY, Hu TX (2020) Moisture content thresholds for ignition and rate of fire spread for various dead fuels in northeast forest ecosystems of China. J For Res. https:// doi.org/10.1007/s11676-020-01162-2

Matvienko OV, Kasymov DP, Filkov AI, Daneyko OI, Gorbatov DA (2018) Simulation of fuel bed ignition by wildland firebrands. Int J Wildland Fire 27:550-561. https://doi.org/10.1071/WF17083

Morandini F, Silvani X, Dupuy JL, Susset A (2018) Fire spread across a sloping fuel bed: flame dynamics and heat transfers. Combust Flame 190:158-170. https://doi.org/10.1016/j.combustflame. 2017.11.025

Oliveira LA, Lopes AG, Baliga BR, Almeida M, Viegas DX (2014) Numerical prediction of size, mass, temperature and trajectory of cylindrical wind-driven firebrands. Int J Wildland Fire 23:698 708. https://doi.org/10.1071/WF13080

Pablo A, Alexis C, Candido GM, Guillermo R (2013) Influence of atrium roof geometries on the numerical predictions of fire tests under natural ventilation conditions. Energy Build 65:382-390. https://doi.org/10.1016/j.enbuild.2013.06.010

Plucinski MP, Anderson WR (2008) Laboratory determination of factors influencing successful 19 point ignition in the litter layer of shrubland vegetation. Int J Wildland Fire 17:628-637. https://doi. org/10.1071/wf07046

Sale PD, Hoffheins FM (1928) Cigarettes and cigars, fire hazard tests. NFPA Q. 21:237-246

Sardoy N, Consalvi JL, Porterie B, Fernandez-Pello AC (2007) Modeling transport and combustion of firebrands from burning trees. Combust Flame 150:151-169. https://doi.org/10.1016/j.combu stflame.2007.04.008

Satho K, Zhong YL, Yang KT (2003) Report of national research of national research institute of fire and disaster. Japan Society of Mechanical Engineers, Japan

Sun P, Zhang Y, Sun L, Hu HH, Guo FT, Wang GY, Zhang H (2018) Influence of fuel moisture content, packing ratio and wind velocity on the ignition probability of fuel beds composed of mongolian oak leaves via cigarette butts. Forests 9:507. https://doi.org/10. 3390/f9090507

Tao Z, Bathras B, Kwon B, Biallas B, Yang R (2020) Effect of firebrand size and geometry on heating from a smoldering pile under wind. Fire Saf J. https://doi.org/10.1016/j.firesaf.2020.103031

Tarifa CS, Notario PP, Moreno FG(1965) On the flight paths and lifetimes of burning particles of wood. Symposium (International) on Combustion, 10, 1021-1037. doi: https://doi.org/10.1016/S00820784(65)80244-2

Viegas DX, Almeida M, Raposo J, Oliveira R, Viegas CX (2012) Ignition of mediterranean fuel beds by several types of firebrands. Fire Technol 50:61-77. https://doi.org/10.1007/s10694-012-0267-8

Wang SP (2016) Experimental and Theoretical Study on Spotting Ignition. Doctor's Thesis, University of Science and Technology of China, Hefei, China. (in Chinese)

Publisher's Note Springer Nature remains neutral with regard to jurisdictional claims in published maps and institutional affiliations. 